Check for updates

Cite this: RSC Adv., 2018, 8, 29155

Received 1st August 2018

Accepted 7th August 2018

DOI: $10.1039 / c 8 r a 06488 a$

rsc.li/rsc-advances

\section{First in situ vesicular self-assembly of 'binols' generated by a two-component aerobic oxidation reaction $\uparrow$ t:}

\begin{abstract}
Braja G. Bag, (D) * Subrata Ghorai, Saikat K. Panja, Shaishab K. Dinda and Koushik Paul
Generation of vesicular self-assemblies from natural and synthetic components has been in the frontiers of research in recent years for an improved understanding of the self-assembly process and also because of its prospective and realized applications in the areas of advanced materials, biotechnology and medicine. In the present work, we report the first example of the in situ generation of vesicular self-assemblies during an aerobic coupling reaction. The two precursor 2-naphthol units, having hydrogen bond donoracceptor groups with appended alkyl chains, yielded binol (2,2'-dihydroxy-1,1'-binaphthyl) derivatives by aerobic coupling that spontaneously self-assembled in situ, yielding vesicular self-assemblies and gels. The morphology of the self-assemblies has been characterized by various optical, electron and atomic force microscopic techniques. The vesicular self-assemblies obtained in the liquids were capable of entrapping fluorophores such as rhodamine-B and carboxy fluorescein including the anticancer drug doxorubicin. The entrapped fluorophores could also be released by sonication or by rupture of vesicles. The supramolecular gels obtained in binary solvent mixtures showed improved gelation abilities with increase in the alkyl chain lengths as reflected by their minimum gelator concentration (mgcs) values, gel to sol transition temperatures $\left(T_{\text {gel }}\right)$ and rheology properties. The results described here are also the first demonstration of gelation during an aerobic coupling reaction.
\end{abstract}

\section{Introduction}

Self-assembly of natural and synthetic molecules yielding supramolecular structures of varied dimensions in the nano to micrometer range has been an area of increasing significance in recent years. These studies have helped scientists to improve the understanding of the structure property relationships that resulted in such supramolecular structures in liquid medium. ${ }^{1-10}$ Spontaneous self-assembly of molecules, yielding vesicles, is of special significance due to its tremendous application in the areas of targeted drug delivery, medical implants, nanoscale reactors, tissue engineering, gene therapy, theranostics, enzyme entrapment, magnetic resonance imaging, etc. ${ }^{11-18}$ Literature studies reveal that vesicular self-assemblies have been reported from a wide range of amphiphilic compounds. ${ }^{19-29}$ Though, the formation of nano-sized spherical assemblies and vesicles in water from long alkyl-chained compounds having different head groups are known, according to our knowledge, aerobic coupling of two components

Department of Chemistry and Chemical Technology, Vidyasagar University, Midnapore 721102,WB, India. E-mail: brajagb@gmail.com

$\dagger$ This paper is dedicated to Professor Guenter von Kiedrowski on his $65^{\text {th }}$ birthday.

‡. Electronic supplementary information (ESI) available. See DOI: 10.1039/c8ra06488a leading to the formation of vesicular self-assemblies and supramolecular nano-architectures in organic media is unprecedented. ${ }^{1-15}$

Binols, obtained by coupling reaction of two $\beta$-naphthol precursors, have found application in the design of asymmetric catalysts for a wide range of chemical transformations. ${ }^{30-36}$ The demonstration of self-replication on non-enzymatic model systems in its minimal form require: (1) suitable complementary recognition sites in the template molecule to complex the precursor molecules by non-covalent interactions and (2) a suitable chemical reaction for the formation of a chemical bond. ${ }^{37-41}$ Computer modeling studies using PCWin ${ }^{\circledR}$ software indicated that the binol derivatives of the type 2 will be able to form a termolecular complex with two precursor 2-naphthol derivatives via complementary H-bond donor-acceptor sites thereby facilitating the autocatalytic template directed synthesis (Fig. 1 and Scheme S1). While carrying out aerobic binol coupling reactions with the 2-naphthol derivatives having $\mathrm{H}$ bond donor-acceptor sites and appended alkyl chains (1b-d), we serendipitously discovered that the binol derivatives (2b-d) spontaneously self-assembled yielding supramolecular gels in the reaction medium. Herein we report the spontaneous formation of vesicular self-assemblies based on three binol derivatives having $\mathrm{H}$-bond donor-acceptor groups with appended alkyl chains in binary solvent mixtures. The self-assemblies have been characterized by atomic force, electron and optical 
microscopic techniques, dynamic light scattering (DLS) and Xray diffraction studies. Entrapment of fluorophores, including drugs and their subsequent release, has also been demonstrated. Moreover, gel-to-sol transition temperatures, various thermodynamic parameters and the rheological properties were investigated for the supramolecular gels obtained in the binary solvent mixtures.

\section{Results and discussion}

\subsection{Syntheses}

Syntheses of compounds 1a-1d were carried out from 6hydroxy-2-naphthoic acid $\mathbf{4}$ and 2-amino-6-picoline 6a following a procedure optimized in our laboratory ${ }^{42}$ The intermediate acid chloride 5 was synthesized in excellent yields from 4 in four steps and then reacted with 2-amino-6-picoline or with its derivatives (6a-6d) in the presence of triethyl amine as a base to produce $7 \mathbf{a}-7 \mathbf{d}$ in $80-90 \%$ yields. On reductive debenzylation of 7b-7d with $\mathrm{H}_{2} / \mathrm{Pd}(\mathrm{C})$ the precursors $\mathbf{1 b}-\mathbf{1 d}$ were obtained in $70-$ $80 \%$ yields. The binol derivatives $2 \mathbf{a}-\mathbf{2 d}$ were synthesized by aerial coupling of $\mathbf{1 a - 1 d}$ in chloroform at room temperature using $\mathrm{CuCl}(\mathrm{OH}) \cdot$ TMEDA as a catalyst in $80-87 \%$ isolated yields. The intermediate acid chloride $\mathbf{5}$ on reaction with $n$-octanol in the presence of triethyl amine as a base produced 8 in $88 \%$ yield. Reductive debenzylation using $\mathrm{H}_{2} / \mathrm{Pd}(\mathrm{C})$ produced 9 in $80 \%$ yield. Aerial coupling of 9 at room temperature in the presence of $\mathrm{CuCl}(\mathrm{OH}) \cdot$ TMEDA as a catalyst produced 3 in $90 \%$ isolated yield.

\subsection{Self-assembly studies}

Compounds of the type $\mathbf{2 a}$, having $\mathrm{H}$-bonding recognition sites, were chosen as templates for autocatalysis via Path A during aerobic coupling of $\mathbf{1 a}$ in the presence of $\mathrm{CuCl}(\mathrm{OH}) \cdot$ TMEDA (Fig. 1). ${ }^{43-45}$ But, compound 1a was soluble only in polar solvents
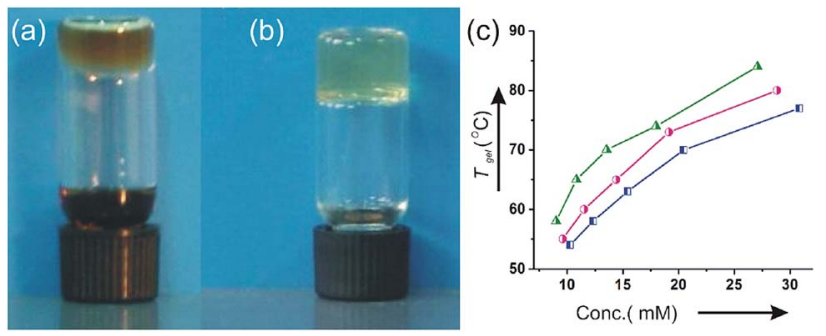

Fig. 2 (a) The $1 b \rightarrow 2 b$ reaction mixture in $6: 1$ hexane-chloroform (b) The gel of pure $2 \mathrm{~b}$ in dodecane-chloroform $(6: 1)$ (c) plot of $T_{\text {gel }} v s$. conc. of $2 b(\square), 2 c(\bigcirc)$ and $2 d(\triangle)$ in cyclohexane-chloroform $(6: 1)$.

such as aliphatic alcohols, DMSO, DMF and remained insoluble in chloroform or dichloromethane. We anticipated that compound 1b having the attached octyloxy chain will have better solubility in aprotic nonpolar solvents. Indeed the compound $\mathbf{1 b}$ was soluble in aprotic solvents like chloroform, dichloromethane, and mixtures of chloroform-hexanes, etc. While carrying out aerobic oxidative coupling of $\mathbf{1 b}$ in hexanechloroform $(6: 1)$ in the presence of $\mathrm{CuCl}(\mathrm{OH}) \cdot \mathrm{TMEDA}$, formation of a heterogeneous soft solid-like material was observed during the progress of the reaction. Monitoring the solution kinetics of the reaction by HPLC (Fig. $2 \mathrm{a}$ and S7\$) was disrupted as well. To explain this observation, we isolated the product $\mathbf{2 b}$ in pure form and dissolved the compound $(10 \mathrm{mM})$ contained in a vial in the same solvent hexane-chloroform (6:1) under hot condition and allowed it to cool at room temperature. On turning the vial upside down after $2 \mathrm{~h}$, no flow of the material was observed and it formed a transparent supramolecular gel (Fig. 2b).

To find out the effect of the longer alkyl chains in the selfassembly process, the decyloxy derivative $2 \mathrm{c}$ and dodecyloxy derivative $2 \mathbf{d}$ were also synthesized ${ }^{35}$ and the self-assembly properties of all the three derivatives $\mathbf{2} \mathbf{b}-\mathbf{2} \mathbf{d}$ were studied in

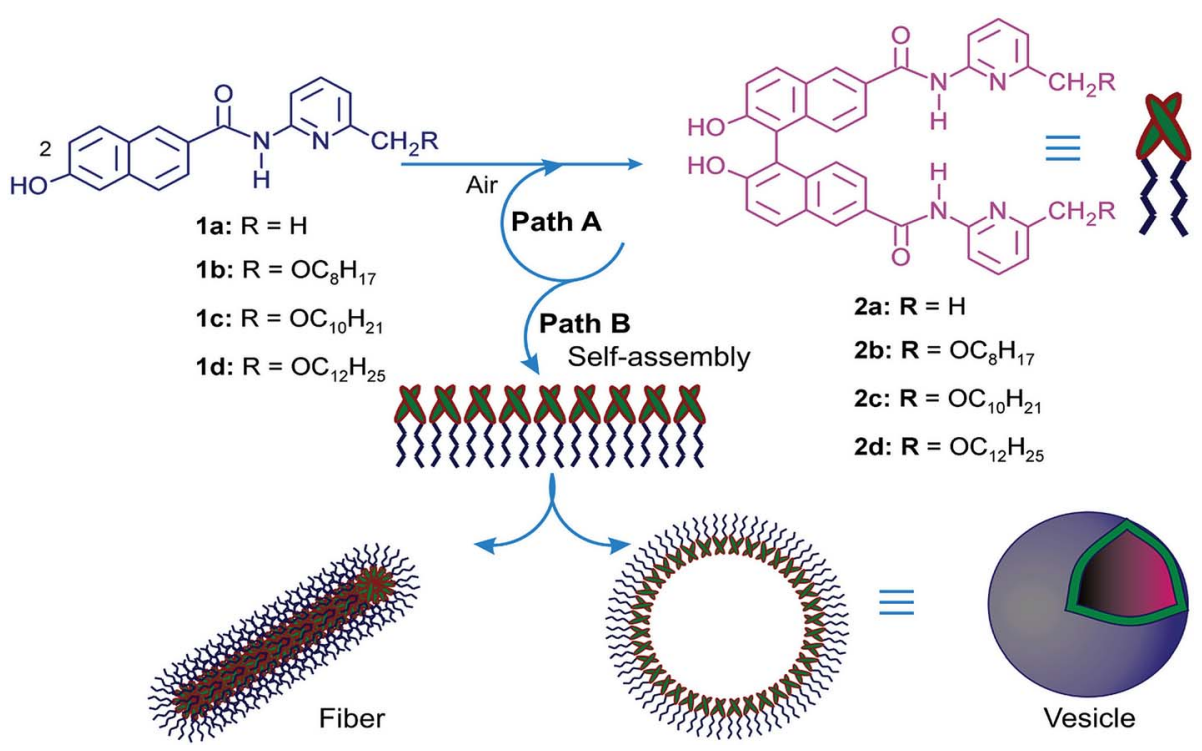

Fig. 1 Aerial oxidation of $\beta$-naphthol units $1 a-d$ yielding binol derivatives $2 a-d$. Path A: schematic representation of self-replication; Path B: schematic representation of the formation of self-assembled $2 b-d$ yielding vesicles. 
Table 1 Results of self-assembly studies of $2 b-2 d$ in binary solvents

\begin{tabular}{|c|c|c|c|c|}
\hline Entry & Solvent ${ }^{a}$ & $2 \mathbf{b}^{b}$ & $2 c^{b}$ & $2 \mathbf{d}^{b}$ \\
\hline 1 & Hexane- $\mathrm{CHCl}_{3}(6: 1)$ & $4.7 / 50$ & $4.0 / 51$ & $3.7 / 53$ \\
\hline 2 & Heptane- $\mathrm{CHCl}_{3}(6: 1)$ & $3.5 / 53$ & $2.9 / 55$ & $2.2 / 58$ \\
\hline 3 & Octane- $\mathrm{CHCl}_{3}(6: 1)$ & $4.9 / 54$ & $4.0 / 56$ & $3.6 / 60$ \\
\hline 4 & Decane- $\mathrm{CHCl}_{3}(6: 1)$ & $3.7 / 59$ & $3.2 / 61$ & $2.7 / 64$ \\
\hline 5 & Dodecane- $\mathrm{CHCl}_{3}(6: 1)$ & $3.7 / 63$ & $2.9 / 65$ & $2.7 / 68$ \\
\hline 6 & $\mathrm{C}_{6} \mathrm{H}_{12}-\mathrm{CHCl}_{3}(6: 1)$ & $4.5 / 48$ & $4.1 / 50$ & $3.9 / 52$ \\
\hline 7 & $\mathrm{C}_{7} \mathrm{H}_{14}-\mathrm{CHCl}_{3}(4: 1)$ & $4.7 / 50$ & $4.0 / 53$ & $3.7 / 55$ \\
\hline 8 & DMSO-water $(5: 1)$ & $5.0 /-$ & $5.0 /-$ & $5.0 /-$ \\
\hline 9 & DMF-water $(5: 1)$ & $5.0 /-$ & $5.0 /-$ & $5.0 /-$ \\
\hline
\end{tabular}

${ }^{a}$ Hexane to dodecane mentioned in entries 1-5 are all normal alkanes. Entry 6: $\mathrm{C}_{6} \mathrm{H}_{12}=$ cyclohexane, entry $7: \mathrm{C}_{7} \mathrm{H}_{14}=$ methyl cyclohexane. ${ }^{b} \mathrm{MGC} / T_{\text {gel }}$ : The minimum gelator concentration (MGC), defined as the minimum concentration required for the formation of a gel, is given in millimolar ( $\mathrm{mM}$ ) unit for each gelator in the binary solvent mixture and its gel to sol transition temperature $T_{\text {gel }}$ in ${ }^{\circ} \mathrm{C}$ at MGC. In entry 8 and 9 colloidal suspensions were obtained at $5 \% \mathrm{w} / \mathrm{v}$ concentration.

different liquids. All the three alkyl chained derivatives were highly soluble in polar organic liquids such as DMF and DMSO. Colloidal suspensions were obtained in DMSO-water and DMFwater binary solvent mixtures. Interestingly, all the derivatives 2b-2d self-assembled in all the seven alkane-chloroform binary solvent mixtures studied forming transparent gels (Table 1). For $\mathbf{2 b}$, the minimum gelator concentrations (MGCs) were in the range of $3.5-4.9 \mathrm{mM}$ in the alkane-chloroform binary solvent mixtures studied. With increasing alkyl chain length from $2 \mathbf{b}$ to 2d, a gradual decrease of MGCs was observed (Table 1) indicating better gelation abilities of the longer alkyl chained derivatives. Repeated heating and cooling experiments carried out with all the gels indicated that all the gels were thermoreversible in nature. The gel to sol transition temperatures $\left(T_{\text {gel }}\right)$ increased with increasing concentration of the gelators. A positive free energy change calculated from the plot of $T_{\text {gel }} v s$. concentration indicated stability of the gels (Fig. S1 $\$$ ).

The gel to sol transition temperatures $\left(T_{\text {gel }}\right)$ increased with increasing concentrations of the gelators in different neat liquids and also in binary liquid mixtures. These data were utilized to calculate the related thermodynamic parameters such as enthalpy, entropy and Gibbs free energy change $\left(\Delta H^{\circ}\right.$, $\Delta S^{\circ}$ and $\Delta G^{\circ}$ ). The positive free energy changes during gel to sol transition in organic binary liquid mixture cyclohexane-chloroform $(6: 1)$ were nearly identical though their enthalpy and entropy changes were slightly different (Table 2). The free energy changes $\left(\Delta G^{\circ}\right)$ calculated during gel to sol transformations were positive in all the cases which is indicative of the stability of the gel phase.

\subsection{Morphology of the self-assemblies}

2.3.1 AFM studies. To investigate the morphology of the self-assemblies, dried self-assemblies of $\mathbf{2 b} \mathbf{b}-\mathbf{2 d}$ prepared from a dilute colloid of $\mathbf{2 b - 2 \mathbf { d }}$ in the binary solvent mixtures were investigated by atomic force microscopy (AFM). Spherical selfassembly of nano to micrometer diameters with an average diameter of $95 \mathrm{~nm}$ were observed (Fig. 3). Co-existence of fibrillar network, along with spherical self-assemblies, was
Table 2 Thermodynamic parameters $\left(\Delta H^{\circ}, \Delta S^{\circ}, \Delta G^{\circ}\right)$ for gel to sol transition of gels of $2 \mathrm{~b}-2 \mathrm{~d}$ in cyclohexane-chloroform (6:1) at $298 \mathrm{~K}$

\begin{tabular}{llll}
\hline Entry & $\begin{array}{l}\Delta H^{\circ} \\
\left(\mathrm{kJ} \mathrm{mol}^{-1}\right)\end{array}$ & $\begin{array}{l}\Delta S^{\circ} \\
\left(\mathrm{J} \mathrm{mol}^{-1} \mathrm{~K}^{-1}\right)\end{array}$ & $\begin{array}{l}\Delta G^{\circ} \\
\left(\mathrm{kJ} \mathrm{mol}^{-1}\right)\end{array}$ \\
\hline 2b & 44.528 & 97.92 & 15.3478 \\
2c & 41.321 & 87.00 & 15.398 \\
2d & 43.139 & 90.50 & 16.150 \\
\hline
\end{tabular}
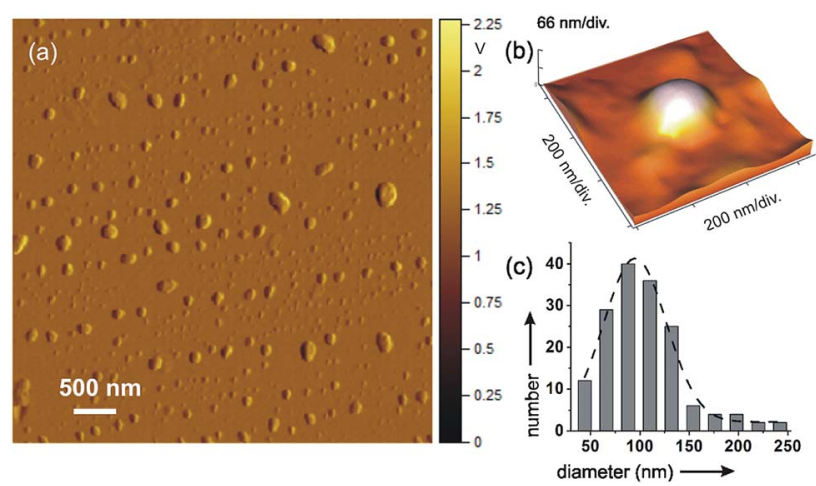

Fig. 3 (a) AFM image of self-assembled $2 c$ in chloroform-cyclohexane $(1: 6 \mathrm{v} / \mathrm{v}, 0.12 \% \mathrm{w} / \mathrm{v})$; (b) $2 \mathrm{~b}$ in dodecane-chloroform $(4: 1 \mathrm{v} / \mathrm{v}$, $0.13 \% \mathrm{w} / \mathrm{v})$; (c) histogram of diameters $(\mathrm{nm})$ of $2 \mathrm{c}$ shown in (a).

observed in the dried self-assemblies of a few samples prepared from the dilute colloid of $\mathbf{2 b - 2 d}$ (Fig. 1 and S2 $\ddagger$ ).

2.3.2 Optical microscopic study. For the investigation of the morphology of the self-assemblies in their native state, optical microscopy was carried out in the liquid state. For this purpose, the self-assemblies of $\mathbf{2 b - 2 d}$ in different organic and aqueous-organic liquid mixtures such as DMSO-water $(5: 1)$, DMF-water $(5: 1)$, cyclohexane-chloroform $(6: 1), n$-octanechloroform $(6: 1)$ etc. below their MGCs were investigated. Spherical self-assemblies of average diameter of $3.6 \mu \mathrm{m}$ were observed in the binary solvent mixtures (Fig. 4 and S3\$). No fibrillar network was observed in the native state. Thus the observation of small percentage of fibrillar network in the dried self-assemblies by AFM (discussed earlier) might be due to a change in morphology during solvent evaporation. Nanosized objects were not observed due to the size limitations using visible light. This limitation could be overcome by electron microscopy of the dried samples of $\mathbf{2} \mathbf{b}-\mathbf{2} \mathbf{d}$ as discussed below.

2.3.3 SEM studies. The self-assemblies of $\mathbf{2 b - 2 d}$ prepared from the dilute colloidal suspensions in cyclohexane-chloroform $(6: 1 \mathrm{v} / \mathrm{v}, 0.11 \% \mathrm{w} / \mathrm{v}), n$-octane-chloroform $(6: 1 \mathrm{v} / \mathrm{v}, 0.11 \%$ $\mathrm{w} / \mathrm{v}$ ) were studied by scanning electron microscopy (SEM). SEM studies of the dried samples in different organic binary liquid mixtures revealed nano-sized vesicular self-assemblies along with microsized vesicular self-assemblies (Fig. 5a and b).

2.3.4 HRTEM studies. To obtain further insight into the morphology of the spherical assemblies of the dried samples of 2b-2d in cyclohexane-chloroform $(6: 1 \mathrm{v} / \mathrm{v}, 0.11 \% \mathrm{w} / \mathrm{v}), n$ octane-chloroform $(6: 1 \mathrm{v} / \mathrm{v}, 0.11 \% \mathrm{w} / \mathrm{v})$, we performed high 


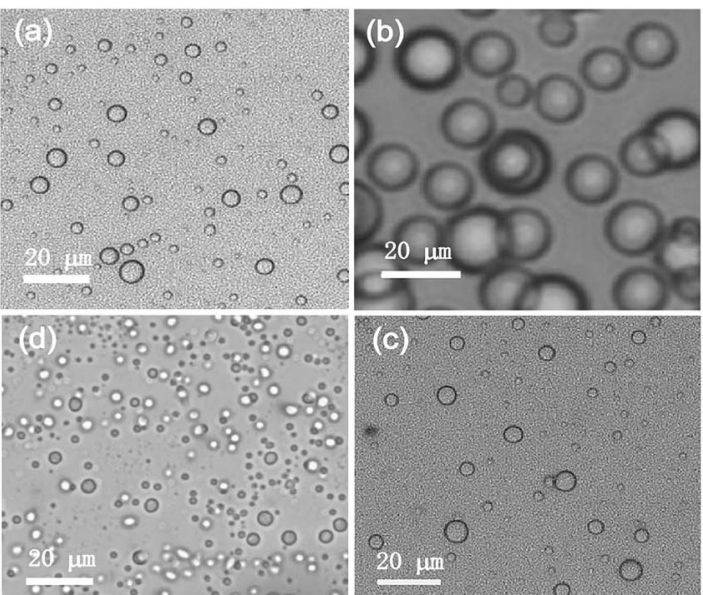

Fig. $4(a-d) O M$ images of (a) $2 d$ in DMSO-water (5: $1 \mathrm{v} / \mathrm{v}, 3.8 \% \mathrm{w} / \mathrm{v})$, (b) $2 \mathrm{~d}$ in DMF-water (5: $1 \mathrm{v} / \mathrm{v}, 3.7 \% \mathrm{w} / \mathrm{v})$, (c) $2 \mathrm{c}$ in DMSO-water $(5: 1 \mathrm{v} /$ $\mathrm{v}, 3.4 \% \mathrm{w} / \mathrm{v}),(\mathrm{d}) 2 \mathrm{c}$ in $\mathrm{DMF}-$ water $(5: 1 \mathrm{v} / \mathrm{v}, 3.5 \% \mathrm{w} / \mathrm{v})$.
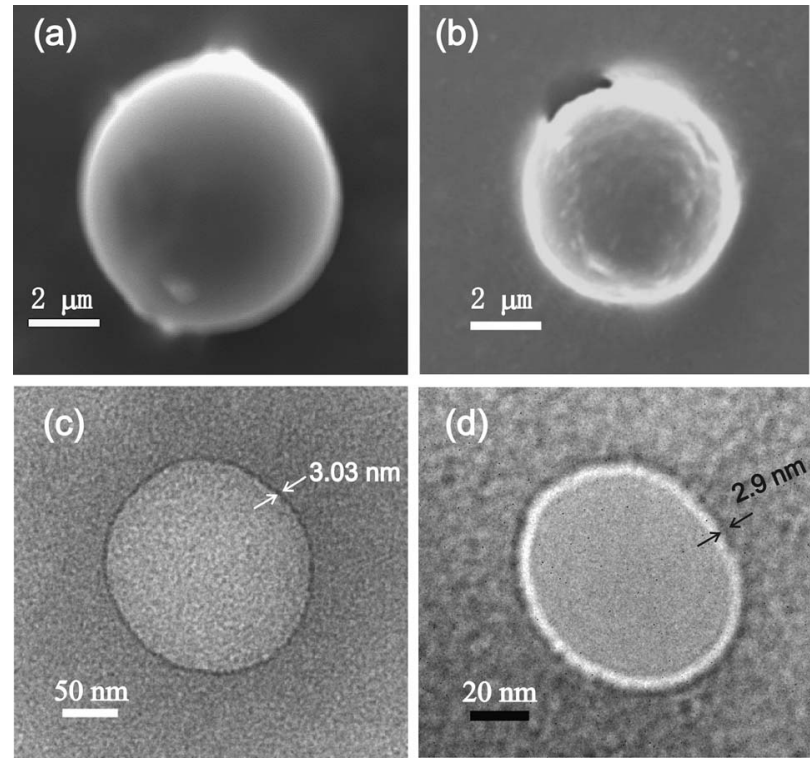

Fig. 5 (a) SEM image of self-assembled $2 d$ in cyclohexane-chloroform (6:1 v/v, 0.11\% w/v), (b) SEM image of self-assembled $2 \mathrm{c}$ in $n$ octane-chloroform $(6: 1 \mathrm{v} / \mathrm{v}, 0.11 \% \mathrm{w} / \mathrm{v})$, (c) HRTEM image of selfassembled $2 d$ in octane-chloroform (6:1 v/v, 0.1\% w/v), (d) HRTEM image of self-assembled $2 \mathrm{c}$ in octane-chloroform $(6: 1 \mathrm{v} / \mathrm{v}, 0.1 \% \mathrm{w} / \mathrm{v})$.

resolution transmission electron microscopy (HRTEM). Nanosized vesicular self-assemblies of $\mathbf{2 b - 2 d}$ were observed by HRTEM in the dried samples prepared from the dilute colloid of 2b-2d in binary organic solvent mixtures (Fig. 5c and d). A distinct periphery in sharp contrast to the inner core confirmed the vesicular nature of the spherical self-assemblies. The membrane thickness of the vesicular self-assemblies was $3.03 \mathrm{~nm}$ for $2 \mathrm{~d}$. With a molecular length of $3.03 \mathrm{~nm}$, a monolayer vesicular membrane is supported. All these observations support the results obtained by scanning electron microscopy, atomic force microscopy and optical microscopy studies (discussed earlier).
2.3.5 X-ray diffraction studies. X-ray diffraction studies carried out with self-assembled $2 \mathbf{c}(0.1 \% \mathrm{w} / \mathrm{v})$ and $2 \mathbf{d}(0.1 \% \mathrm{w} / \mathrm{v})$ in DMSO-water $(5: 1)$ revealed peaks at $2 \theta=3.05^{\circ}$ and $2.9^{\circ}$ corresponding to $d$ values of $2.9 \mathrm{~nm}$ and $3.03 \mathrm{~nm}$ respectively that also supported a monolayer vesicular self-assembly (Fig. S4) as depicted in Fig. 1 (Path B).

2.3.6 DLS studies. DLS studies were carried out with the self-assemblies of binol derivatives $\mathbf{2 c}$ and $\mathbf{2 d}$ in the binary solvent mixtures at room temperature. Evidence for the presence of polydisperse self-assemblies of nano- to micro-meter diameters was obtained (Fig. S5 $\$$ ). This explains our observation for the presence of both nano- to micro-sized selfassemblies by AFM, SEM and TEM studies (discussed earlier). Only micro-sized vesicular self-assemblies observed by optical microscopy under visible light was due to limitation of the technique used.

2.3.7 FTIR studies. Various non-covalent interactions such as H-bonding, van der Waals, solvophobic, aromatic-aromatic, electrostatic, lipophilic interactions have been considered as the major driving forces for gelation. The self-assembly of the compounds $\mathbf{2 b - \mathbf { d }}$ in aprotic nonpolar liquids may have been driven by the intermolecular $\mathrm{H}$-bonding from the $\mathrm{CO}-\mathrm{NH} \mathrm{H}$ bond donor and acceptor groups, aromatic-aromatic interaction from the binol head groups and dispersive interactions from the large lipophilic alkyl chains. To investigate the role of $\mathrm{H}$-bonding in gelation, FTIR spectra were recorded for the derivatives in solution and the gel states and their stretching frequencies were compared. The shifting of the $\mathrm{NH}$ and $\mathrm{CO}$ stretching frequencies in the gel state of $2 \mathbf{b}\left(3436.5 \mathrm{~cm}^{-1}\right.$ and $1676.8 \mathrm{~cm}^{-1}$ respectively) to a higher frequency in its solution state after 16 times dilution $\left(3441.3 \mathrm{~cm}^{-1}\right.$ and $1685.5 \mathrm{~cm}^{-1}$ respectively) indicated stronger intermolecular $\mathrm{H}$-bonding during gelation (Fig. 7). The model compound 3 (Scheme 1) without H-bonding groups did not form gel under identical condition also indicated the role of $\mathrm{H}$-bonding during the self assembly.

2.3.8 Rheology study of gels. Gels are soft solid-like or more specifically viscoelastic materials and hence it exhibit both storage and dissipation of energy characterized by the storage and loss moduli $G^{\prime}$ and $G^{\prime \prime}$ respectively. Dynamic rheology experiments enable us to know various important mechanical properties of the gels. A rheometer with a plate-plate assembly equipped with a Peltier temperature control system where the upper plate had a diameter of $25 \mathrm{~mm}$ was used for all rheological measurements. All the rheology experiments were performed at $25{ }^{\circ} \mathrm{C}$ in binary liquid mixtures keeping a gap size of $0.4 \mathrm{~mm}$ between the plates to minimize solvent evaporation during the experiments. ${ }^{46}$ Amplitude sweep and frequency sweep experiments were carried out with the gels obtained from 2c and 2d in octane-chloroform (6:1) (Fig. 6). In amplitude sweep experiment applying the shear strain ramp (0.01-100\%), it was observed that with increasing strain, $G^{\prime}$ started to decrease in a critical strain after passing the linear region. For both the samples, no crossover point $\left(G^{\prime}=G^{\prime \prime}\right)$ was observed indicating that both the gels were very strong. The longer linear region observed for the gel from $\mathbf{2 d}$ (Fig. 6a) compared to that 

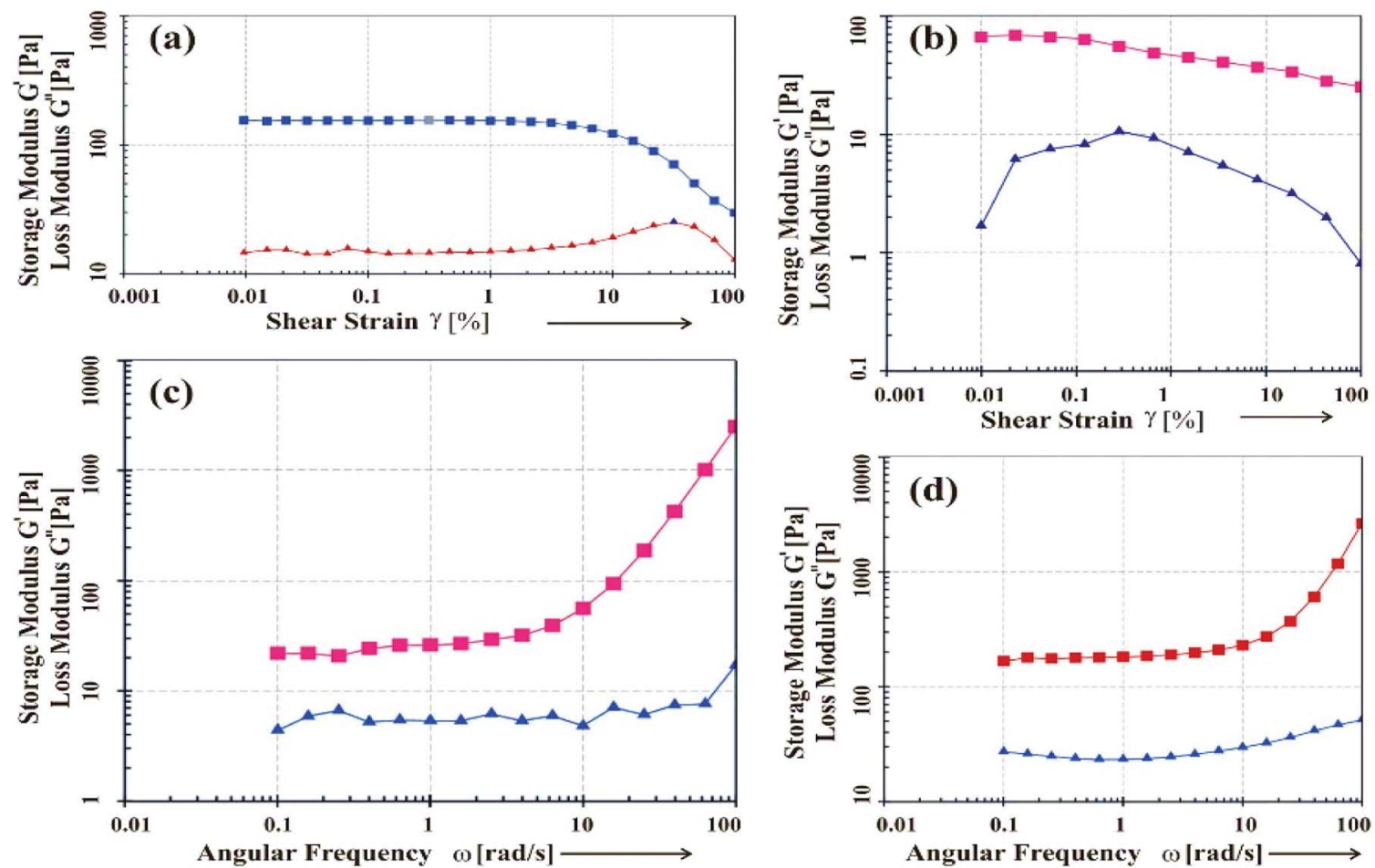

Fig. 6 Rheological plots of the gels of 2c, $2 d$ in octane-chloroform (6:1): (a and b) $G^{\prime}, G^{\prime \prime}$ vs. shear strain (\%), and (c and d) $G^{\prime}, G^{\prime \prime} v s$. angular frequency.
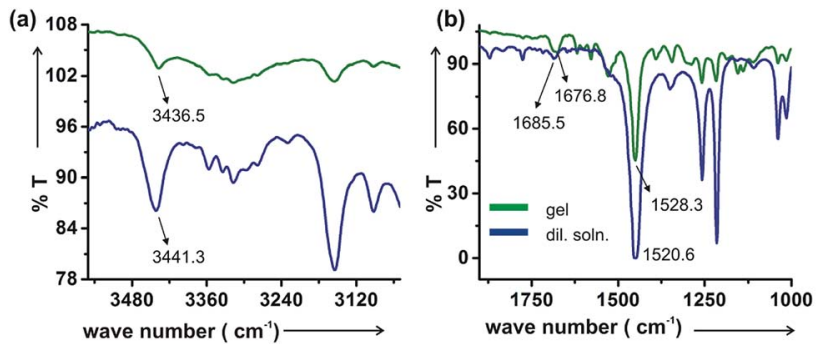

Fig. 7 FTIR of $2 \mathrm{~b}$ in gel state $(18.6 \mathrm{mM})$ and after 16 times dilution (1.16 $\mathrm{mM})$. In the gel state the $\mathrm{N}-\mathrm{H}$ stretching frequency is at lower wave number $\left(3436.5 \mathrm{~cm}^{-1}\right)$ than in that in the diluted condition $\left(3441.3 \mathrm{~cm}^{-1}\right)$. Similarly, the $\mathrm{C}=\mathrm{O}$ stretching frequency is at lower wave number $\left(1676.8 \mathrm{~cm}^{-1}\right)$ in the gel state than that in the diluted state $\left(1685.5 \mathrm{~cm}^{-1}\right)$. In contrast the $\mathrm{N}-\mathrm{H}$ bending is at higher wavenumber $\left(1528.3 \mathrm{~cm}^{-1}\right)$ in the gel state than that after dilution $\left(1520.6 \mathrm{~cm}^{-1}\right)$.

from 2c (Fig. 6b) indicated that 2d with a longer alkyl chain was a better gelator compared to $2 \mathbf{c}$. This result is also supported by the gel to sol transition temperatures $\left(T_{\text {gel }}\right)$ (as discussed previously in Section 2).

The frequency sweep experiments (Fig. 6c and d), were carried out by applying angular frequency $=0.01-100 \mathrm{rad} \mathrm{s}^{-1}$, at a constant temperature $\left(25^{\circ} \mathrm{C}\right)$. An increase in $G^{\prime}$ and $G^{\prime \prime}$ were observed with increase in angular frequency. This can be explained by the fact that, with an increase in oscillatory frequency, the gel network vibrate rapidly and were unable to rearrange themselves in the imposed motion. As a result, it showed solid like behavior at higher frequency compared to lower frequency. Thus to breakdown the gel network, greater shear strain is required at higher frequency than that of lower frequency. ${ }^{47,48}$ Thus, both in frequency sweep as well as amplitude sweep experiments, an increase in $G^{\prime}$ and $G^{\prime \prime}$ were observed with increase in frequency and \% shear strain respectively. These results indicated the gel behavior and elastic nature of the organogels in the binary liquid mixtures studied.

\subsubsection{Utilization of binol-derived vesicular self-assemblies}

2.3.9.1 Entrapment of fluorophores. Initial entrapment studies of binol derived vesicular self-assemblies of $\mathbf{2 c}$ and $2 \mathbf{2 d}$ were carried out with a cationic fluorophore rhodamine B (RhoB) hydrochloride and an anionic fluorophore 5,6-carboxyfluorescein (CF). Bright green and red fluorescence observed from the vesicular self-assemblies under fluorescence light indicated that both the fluorophores Rho-B and CF were entrapped inside the vesicular self-assemblies of $\mathbf{2 c}$ and $\mathbf{2 d}$ (Fig. 8a-e). Such observation have been made by us previously with the vesicular self-assemblies of naturally occurring diterpenic and hydroxy-triterpenic acids. ${ }^{49-51}$ These observations inspired us to examine the entrapment of doxorubicin (Dox), a well-known anticancer drug having fluorescence properties. A solution of 2c (47 mM) and Dox (0.47 mM) in DMSO-water (5 : 1 $\mathrm{v} / \mathrm{v}$ ) at $45{ }^{\circ} \mathrm{C}$ was cooled at room temperature and the resulting colloidal suspension was examined after $4 \mathrm{~h}$. Bright fluorescence from the core of the vesicular self-assemblies of $2 \mathbf{c}$ under epifluorescence microscope confirmed the entrapment of Dox inside the vesicles (Fig. 8c and f). Quenching of fluorescence at $560 \mathrm{~nm}$ during entrapment of Rho-B inside the vesicles compared to free Rho-B $\left(\lambda_{\mathrm{ex}}=520 \mathrm{~nm}\right)$ was also observed 
<smiles>CC(=O)c1ccc2cc(OCc3ccccc3)ccc2c1</smiles><smiles>[R]Cc1cccc(N)n1</smiles>

6a: $\mathrm{R}=\mathrm{H}$

6b: $\mathrm{R}=\mathrm{OC}_{8} \mathrm{H}_{17}$

6c: $R=O_{10} \mathrm{H}_{21}$

6d: $\mathrm{R}=\mathrm{OC}_{12} \mathrm{H}_{25}$<smiles>[R]Cc1cccc(NC(=O)c2ccc3cc(OCc4ccccc4)ccc3c2)n1</smiles>

7a: $\mathrm{R}=\mathrm{H}$

$7 b: R=O_{8} \mathrm{H}_{17}(70 \%)$

7c: $\mathrm{R}=\mathrm{OC}_{10} \mathrm{H}_{21}(95 \%)$

7d: $\mathrm{R}=\mathrm{OC}_{12} \mathrm{H}_{25}(95 \%)$

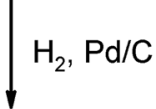<smiles></smiles>

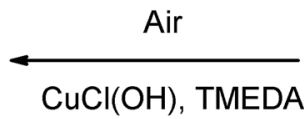<smiles>[R]Cc1cccc(NC(=O)c2ccc3cc(O)ccc3c2)n1</smiles>

1a: $\mathrm{R}=\mathrm{H}$

1b: $\mathrm{R}=\mathrm{OC}_{8} \mathrm{H}_{17}(70 \%)$

1c: $\mathrm{R}=\mathrm{OC}_{10} \mathrm{H}_{21}(89 \%)$

1d: $\mathrm{R}=\mathrm{OC}_{12} \mathrm{H}_{25}(75 \%)$

2d: $\mathbf{R}=\mathrm{OC}_{12} \mathrm{H}_{25}(87 \%)$<smiles>CCO[C@H](C)c1ccccc1</smiles><smiles>O=C(O[Ga])c1ccc2cc(OCc3ccccc3)ccc2c1</smiles><smiles>CCCCCC</smiles>

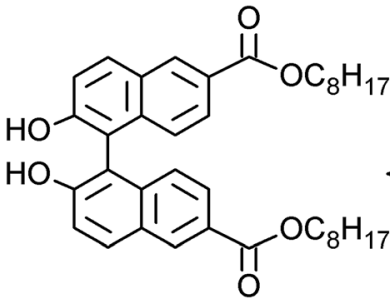

$3(87 \%)$<smiles>O=C(O[Ga])c1ccc2cc(O)ccc2c1</smiles>

$9(98 \%)$

Scheme 1 Syntheses of the precursor molecules $1 \mathrm{a}-1 \mathrm{~d}$, template molecules $2 \mathrm{a}-\mathbf{2} \mathrm{d}$ and the model compound 3 .

(Fig. 9A, B and E) confirming the entrapment of Rho-B inside the vesicles. Successful entrapment of guest molecules including drugs inside the vesicular self-assemblies of binol derivatives having an average diameter $<10 \mu \mathrm{m}$ and their release studies open up its use in cell signaling, ${ }^{52}$ clinical diagnosis ${ }^{53}$ including targeted delivery through blood capillaries. ${ }^{54-57}$

2.3.9.2 Release of entrapped guest molecules. To examine the release of the entrapped guest molecules from the vesicular self-assemblies of binol derivatives, sonication of the RhoB entrapped vesicular self-assemblies of $2 d$ was carried out in an ultrasonicator bath. Gradual increase in fluorescence emission intensity at $560 \mathrm{~nm}\left(\lambda_{\text {ex }}=520 \mathrm{~nm}\right)$ indicted the release of entrapped Rho-B from the vesicular self-assemblies (Fig. S6 $\$$ ). For chemical rupture of the Rho-B entrapped vesicular self-assemblies, the Rho-B (0.41 $\mathrm{mM})$ entrapped vesicular self-assemblies of $2 \mathbf{d}(41 \mathrm{mM})$ were treated with a small amount of triton X-100 (0.41 mM), a well-known vesicle rupturing agent. Disappearance of the bright fluorescent spherical images within 2-3 hours with concomitant appearance of an intense background under epifluorescence microscope indicated the lysis of the vesicles (Fig. 9C, D and F) with concomitant release of the fluorophore Rho-B. ${ }^{55}$ 

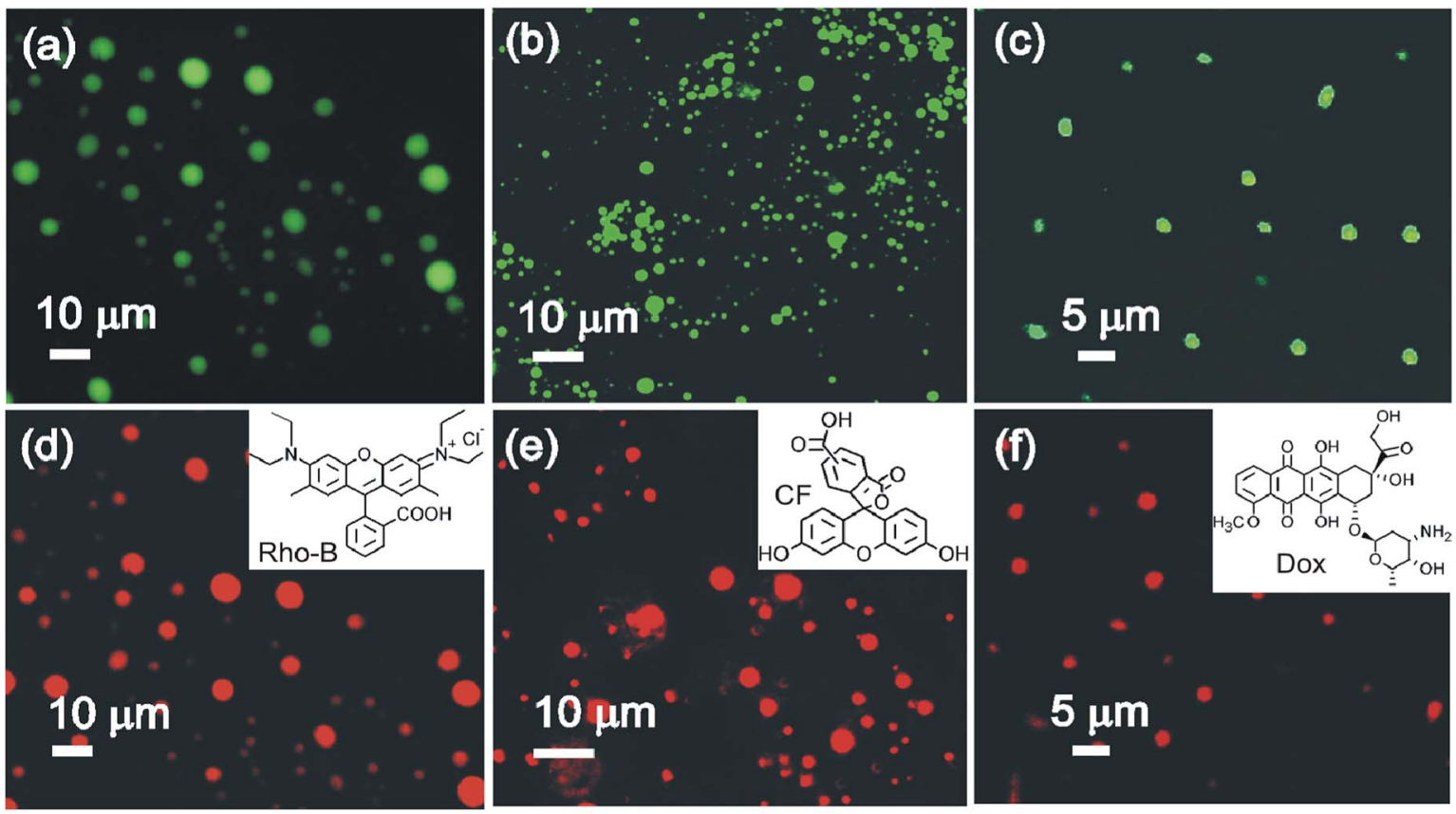

Fig. 8 Fluorescent micrographs of self-assembled $2 b-2 d$ in DMSO-water (5: 1): ( $a$ and d) self-assembled $2 d$ ( $41 \mathrm{mM}$ ) containing Rho-B (0.41 $\mathrm{mM}$ ) exposed under blue and green emission light, ( $b$ and e) self-assembled $2 \mathrm{c}(43 \mathrm{mM})$ containing $\mathrm{CF}(0.43 \mathrm{mM})$ exposed under blue and green emission light, ( $c$ and f) self-assembled $2 c(47 \mathrm{mM})$ containing Dox $(0.47 \mathrm{mM})$ exposed under blue and green emission light.

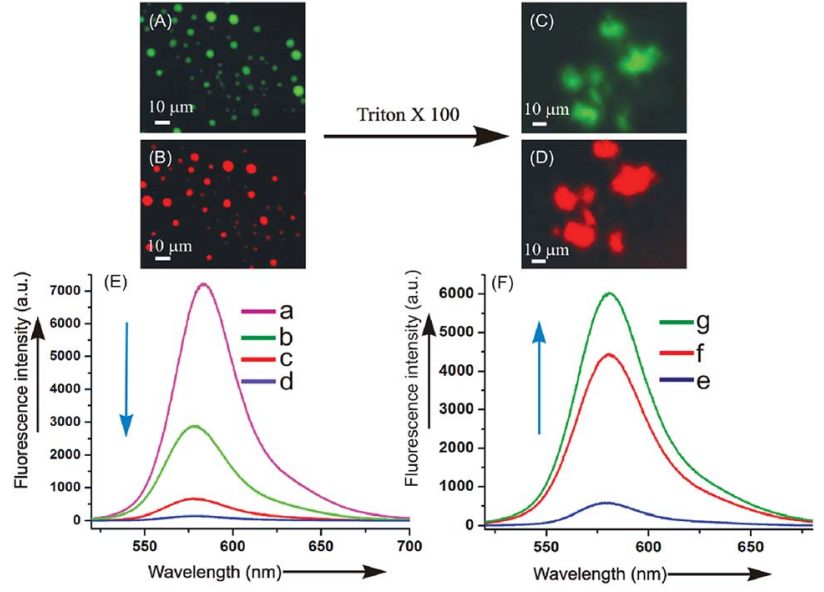

Fig. 9 Entrapment and subsequent release of Rho-B from the vesicular self-assemblies: (A and B) fluorescent micrographs of selfassembled $2 \mathrm{~d}(41 \mathrm{mM})$ containing Rho-B $(0.41 \mathrm{mM})$ exposed under blue and green emission light, ( $C$ and $D)$ : fluorescent micrographs after the addition of triton $X-100(0.41 \mathrm{mM})$ into the Rho-B entrapped vesicular self-assembly of $2 \mathrm{~d}$. (E) Fluorescence emission spectra $\left(\lambda_{\max (\text { ex. })} 520 \mathrm{~nm}\right)$ of free and encapsulated Rho-B inside the vesicular self-assemblies of $2 d$ at different time intervals: $(a)=$ free Rho- $B$ (3.45 $\mu M),(b-d)=2 d(0.345 \mathrm{mM})$ and Rho- $B 1 \mathrm{~h}, 3 \mathrm{~h}$ and $24 \mathrm{~h}$ respectively, (F) fluorescence emission spectra of the release of Rho-B by triton $\mathrm{X}$ 100 at different time intervals: (e) $=1 \mathrm{~h},(\mathrm{f})=3 \mathrm{~h},(\mathrm{~g})=24 \mathrm{~h}$.

\section{Conclusions}

In conclusion, spontaneous formation of vesicular selfassemblies during an aerobic coupling reaction of two monomeric components has been demonstrated. According to our knowledge, this is the first report of the formation of vesicular self-assemblies and gels from compounds obtained by in situ coupling of two components. Detailed characterization of the vesicular self-assemblies has been carried out by atomic force, optical, electron microscopic techniques and Xray diffraction studies. Entrapment of cationic fluorophore rhodamine $\mathrm{B}$, anionic fluorophore carboxyfluorescein and a commonly used anticancer drug doxorubicin in the selfassemblies has been demonstrated. The entrapped fluorophores could be released by sonication and by rupture of vesicles. Gel to sol transition temperatures data for the gels enabled us to calculate the $\Delta G, \Delta H$ and $\Delta S$ values during gel to sol transitions. Improved gelation abilities of the gelators with an increase in the alkyl chain lengths were also observed, as reflected by their minimum gelator concentration, $T_{\text {gel }}$ values and rheology properties. Dynamic rheology experiments carried out with the gels showed no cross over points between the storage $\left(G^{\prime}\right)$ and the loss $\left(G^{\prime \prime}\right)$ moduli indicating that the supramolecular gels obtained in the binary solvent mixtures were very strong in nature.

\section{Experimental section}

\subsection{General information}

For general information regarding conditions for NMR, optical microscopy, fluorescence microscopy, SEM, HRTEM, AFM, DLS, XRD and rheological studies, please see ESI.\$ 


\subsection{Synthesis}

General procedure for the syntheses of binol derivatives $\mathbf{2 a - 2 d}$ and the model compound $\mathbf{3}$ by taking the synthesis of $\mathbf{2 d}$ from 1d as a representative example:

4.2.1 Synthesis of $2 d$. A solution of compound 1d (0.105 g, $0.23 \mathrm{mmol})$ in chloroform $(1 \mathrm{~mL})$ was treated with a solution of $\mathrm{CuCl}(\mathrm{OH}) \cdot$ TMEDA $(0.0053 \mathrm{~g}, 0.023 \mathrm{mmol})$ in chloroform $(0.2$ $\mathrm{mL}$ ) and the reaction mixture was stirred at room temperature for $8 \mathrm{~h}$ maintaining an equilibrium with atmospheric oxygen. After removal of the volatiles under reduced pressure, purification was carried out by column chromatography (Si-gel, 100200 mesh) using 30\% ethyl acetate/petroleum ether as eluent yielding $2 \mathbf{d}$ ( $0.092 \mathrm{~g}$, yield: $87 \%$ ) as a yellowish solid. $\mathrm{Mp}=120$ $130{ }^{\circ} \mathrm{C}$, FTIR (neat, $\mathrm{cm}^{-1}$ ) $\nu_{\text {max }}: 3472,3448,3429,3409,2927$, 2856, 1671, 1623, 1526, 802. ${ }^{1} \mathrm{H}$ NMR (400 MHz, $\left.\mathrm{CDCl}_{3}\right): \delta=8.60$ $(\mathrm{s}, 2 \mathrm{H}), 8.29(\mathrm{~s}, 2 \mathrm{H}), 8.20(\mathrm{~d}, J=8.4 \mathrm{~Hz}, 2 \mathrm{H}), 7.85(\mathrm{~d}, J=8.4 \mathrm{~Hz}$, $2 \mathrm{H}), 7.75-7.72(\mathrm{t}, 2 \mathrm{H}), 7.47(\mathrm{~d}, J=8.4 \mathrm{~Hz}, 2 \mathrm{H}), 7.16(\mathrm{~d}, J=7.8 \mathrm{~Hz}$, $2 \mathrm{H}), 7.0(\mathrm{~d}, J=8.4 \mathrm{~Hz}, 2 \mathrm{H}), 4.46(\mathrm{~d}, J=17.4 \mathrm{~Hz}, 4 \mathrm{H}), 3.47-3.45(\mathrm{t}$, $4 \mathrm{H}), 1.56-1.51(\mathrm{~m}, 4 \mathrm{H}), 1.33-1.18(\mathrm{~m}, 36 \mathrm{H}), 0.88-0.85(\mathrm{t}$, $6 \mathrm{H})$ ppm. ${ }^{13} \mathrm{C}$ NMR $\left(100 \mathrm{MHz}, \mathrm{CDCl}_{3}\right): \delta=156.09,156.60$, 155.23, 150.83, 139.25, 135.67, 132.06, 128.62, 128.45, 128.27, $124.85,124.59,120.02,117.67,113.08,113.03,73.01,71.45$, $31.89,29.64,29.61,29.60,29.57,29,54,29.45,29.33,26.06$, 22.66, 14.11 ppm. HRMS: $m / z$ calcd for $\mathrm{C}_{58} \mathrm{H}_{74} \mathrm{~N}_{4} \mathrm{O}_{6} \mathrm{Na}\left[\mathrm{M}+\mathrm{Na}^{+}\right]$ 923.5912; found 923.5910 .

4.2.2 Synthesis of 2a. Isolated yield of 2 a synthesized from $1 \mathrm{a}(0.07 \mathrm{~g} 0.26 \mathrm{mmol})$ in $\mathrm{THF} / \mathrm{MeOH}(8 \mathrm{~mL}, 3: 1 \mathrm{v} / \mathrm{v})$ as a reaction medium in the presence of $\mathrm{CuCl}(\mathrm{OH}) \cdot \mathrm{TMEDA}(0.006 \mathrm{~g}$, $0.027 \mathrm{mmol})$ was $0.056 \mathrm{~g}(80 \%)$ as a white solid. $\mathrm{Mp}>360{ }^{\circ} \mathrm{C}$, FTIR (neat, $\mathrm{cm}^{-1}$ ) $\nu_{\max }: 3363,2964,1672,1611,1533 .{ }^{1} \mathrm{H}$ NMR $\left(400 \mathrm{MHz}\right.$, DMSO$\left.^{-\mathrm{d}_{6}}\right): \delta=8.524(\mathrm{~s}, 2 \mathrm{H}), 8.042(\mathrm{~d}, J=8.2 \mathrm{~Hz}, 2 \mathrm{H})$, $7.92(\mathrm{~d}, J=8.8 \mathrm{~Hz}, 2 \mathrm{H}), 7.72-7.53(\mathrm{~m}, 4 \mathrm{H}), 7.38(\mathrm{~d}, J=9.0 \mathrm{~Hz}$, 2H), 7.07 (d, $J=8.4 \mathrm{~Hz}, 2 \mathrm{H}), 6.86$ (d, $J=7.4 \mathrm{~Hz}, 2 \mathrm{H}), 4.43$ (broad s, 2H) ppm. $\left.{ }^{13} \mathrm{C} \mathrm{NMR} \mathrm{(100} \mathrm{MHz,} \mathrm{CDCl}_{3}\right): \delta=166.44$, $157.1,155.47,151.98,138.90,136.25,131.03,129.57,128.23$, $127.47,125.01,124.68,119.78,119.45,115.60,111.98$, 24.04 ppm. HRMS (ESI): $m / z$ calcd for $\mathrm{C}_{34} \mathrm{H}_{26} \mathrm{~N}_{4} \mathrm{O}_{4} \mathrm{Na}\left[\mathrm{M}+\mathrm{Na}^{+}\right]$ 554.5947 ; found 554.5949 .

4.2.3 Synthesis of $2 \mathbf{b}$. Isolated yield of $2 \mathbf{b}$ synthesized from 1 b $(0.05 \mathrm{~g}, 0.11 \mathrm{mmol})$ in chloroform $(5 \mathrm{~mL})$ as a reaction medium in the presence of $\mathrm{CuCl}(\mathrm{OH}) \cdot \operatorname{TMEDA}(0.0026 \mathrm{~g}, 0.011$ $\mathrm{mmol})$ was $0.042 \mathrm{~g}(84 \%)$ as a yellowish solid. $\mathrm{Mp}=167-170{ }^{\circ} \mathrm{C}$, FTIR (neat, $\mathrm{cm}^{-1}$ ) $\nu_{\text {max }}: 3320,2926,2856,1671,1601,1580$, 1530, 14.10. ${ }^{1} \mathrm{H}$ NMR (400 MHz, $\left.\mathrm{CDCl}_{3}\right): \delta=8.55(\mathrm{~s}, 2 \mathrm{H}), 8.28-$ $8.17(\mathrm{~m}, 4 \mathrm{H}), 7.87-7.69(\mathrm{~m}, 4 \mathrm{H}), 7.45(\mathrm{~d}, J=8.8 \mathrm{~Hz}, 2 \mathrm{H}), 7.22-$ $6.97(\mathrm{~m}, 4 \mathrm{H}), 4.44(\mathrm{~s}, 4 \mathrm{H}), 3.46(\mathrm{t}, 4 \mathrm{H}), 1.56-1.46(\mathrm{~m}, 4 \mathrm{H}), 1.31-$ $1.23(\mathrm{~m}, 20 \mathrm{H}), 0.84(\mathrm{t}, 6 \mathrm{H}) \mathrm{ppm} .{ }^{13} \mathrm{C} \mathrm{NMR}\left(100 \mathrm{MHz}, \mathrm{CDCl}_{3}\right): \delta=$ 166.70, 154.92, 135.94, 133.05, 131.39, 128.49, 127.03, 126.03, 124.21, 118.81, 110.90, 65.32, 31.81, 29.28, 29.22, 28.76, 26.08, 22.66 ppm. HRMS (ESI): $m / z$ calcd for $\mathrm{C}_{50} \mathrm{H}_{60} \mathrm{~N}_{4} \mathrm{O}_{6} \mathrm{Na}\left[\mathrm{M}+\mathrm{Na}^{+}\right]$ 811.4254; found 811.4257.

4.2.4 Synthesis of 2c. Isolated yield of $2 \mathrm{c}$ synthesized from $1 \mathrm{c}(0.13 \mathrm{~g}, 0.29 \mathrm{mmol})$ in chloroform $(5 \mathrm{~mL})$ as a reaction medium in the presence of $\mathrm{CuCl}(\mathrm{OH}) \cdot$ TMEDA (0.007 $\mathrm{g}, 0.03$ $\mathrm{mmol})$ was $0.110 \mathrm{~g},(85 \%)$ as a yellowish solid. $\mathrm{Mp}=134-136^{\circ} \mathrm{C}$; FTIR (neat, $\mathrm{cm}^{-1}$ ) $\nu_{\max } 3470,3447,3428,3406,2926,2855,1671$,
1622, 1526, 799. ${ }^{1} \mathrm{H}$ NMR (400 MHz, $\left.\mathrm{CDCl}_{3}\right): \delta=8.52(\mathrm{~s}, 2 \mathrm{H})$, $8.05(\mathrm{~d}, J=9.2 \mathrm{~Hz}, 2 \mathrm{H}), 7.83(\mathrm{~d}, J=8 \mathrm{~Hz}, 2 \mathrm{H}), 7.44(\mathrm{~d}, J=8.8 \mathrm{~Hz}$, $2 \mathrm{H}), 7.10(\mathrm{~d}, J=8.8 \mathrm{~Hz}, 2 \mathrm{H}), 5.61(\mathrm{~s}, 2 \mathrm{H}), 4.29(\mathrm{~m}, 4 \mathrm{H}), 1.80-1.73$ (m, 4H), 1.44-1.21 (m, 20H), $0.87(\mathrm{t}, 6 \mathrm{H}) \mathrm{ppm} .{ }^{13} \mathrm{C}$ NMR (100 $\left.\mathrm{MHz}, \mathrm{CDCl}_{3}\right): \delta=166.70,154.92,135.94,133.05,131.39,128.49$, 127.03 , 126.03, 124.21, 118.81, 110.90, 65.32, 31.81, 29.28, 29.22, 28.76, 26.08, 22.66, $14.10 \mathrm{ppm}$. HRMS (ESI) $\mathrm{m} / \mathrm{z}$ : calcd for $\mathrm{C}_{54} \mathrm{H}_{66} \mathrm{~N}_{4} \mathrm{O}_{6} \mathrm{Na}\left[\mathrm{M}+\mathrm{Na}^{+}\right]$867.5055; found 867.5058.

4.2.5 Synthesis of compound 3. Isolated yield of 3 synthesized from $6(0.08 \mathrm{~g}, 0.27 \mathrm{mmol})$ in chloroform $(5 \mathrm{~mL})$ as a reaction medium in the presence of $\mathrm{CuCl}(\mathrm{OH}) \cdot$ TMEDA $(0.0062 \mathrm{~g}, 0.027 \mathrm{mmol})$ was $0.072 \mathrm{~g},(87 \%)$ as a yellowish solid. $\mathrm{Mp}=134-136{ }^{\circ} \mathrm{C},{ }^{1} \mathrm{H}$ NMR $\left(400 \mathrm{MHz}, \mathrm{CDCl}_{3}\right): \delta=8.52(\mathrm{~s}, 2 \mathrm{H})$, $8.05(\mathrm{~d}, J=9.2 \mathrm{~Hz}, 2 \mathrm{H}), 7.83(\mathrm{~d}, J=8.8 \mathrm{~Hz}, 2 \mathrm{H}), 7.44$ (d, $J=$ $8.8 \mathrm{~Hz}, 2 \mathrm{H}), 7.10(\mathrm{~d}, J=8.8 \mathrm{~Hz}, 2 \mathrm{H}), 5.61(\mathrm{~s}, 2 \mathrm{H}), 4.29(\mathrm{~m}, 4 \mathrm{H})$, 1.80-1.73 (m, 4H), 1.44-1.21 (m, 20H), $0.87(\mathrm{t}, 6 \mathrm{H}) .{ }^{13} \mathrm{C} \mathrm{NMR}$ $\left(100 \mathrm{MHz}, \mathrm{CDCl}_{3}\right): \delta=166.70,154.92,135.94,133.05,131.39$, $128.49,127.03,126.03,124.21,118.81,110.90,65.32,31.81$, 29.28, 29.22, 28.76, 26.08, 22.66, $14.10 \mathrm{ppm}$. HRMS (ESI): $\mathrm{m} / \mathrm{z}$ calcd for $\mathrm{C}_{38} \mathrm{H}_{46} \mathrm{O}_{6} \mathrm{Na}\left[\mathrm{M}+\mathrm{Na}^{+}\right]$598.7824; found 598.7821.

\section{Conflicts of interest}

“There are no conflicts to declare".

\section{Acknowledgements}

DST Fast-Track (SR/FTP/CS-42/2001), SERB (EMR/2016/001123), Indo-Srilanka project (DST/INT/SL/P25/2016), UGC-SAP and DST-FIST, Vidyasagar University are gratefully acknowledged for providing financial support and infrastructural facilities. S. K. D., K. P., S. G. thank CSIR and S. G., S. K. P. thank UGC-BSR for providing research fellowships.

\section{References}

1 S. Bhattacharya and S. K. Samanta, Chem. Rev., 2016, 116, 11967-12028.

2 S. S. Babu, V. K. Praveen and A. Ajayaghosh, Chem. Rev., 2014, 114, 1973-2129.

3 A. Sorrenti, O. Illa and R. M. Ortuno, Chem. Soc. Rev., 2013, 42, 8200-8219.

4 M. B. Avinash and T. Govindaraju, Acc. Chem. Res., 2018, 51, 414-426.

5 L. Wang and Q. Li, Chem. Soc. Rev., 2018, 47, 1044-1097.

6 C. Wang, Z. Wang and X. Zhang, Acc. Chem. Res., 2012, 45, 608-618.

7 E. Carretti, M. Bonini, L. Dei, B. H. Berrie, L. V. Angelova, P. Baglioni and R. G. Weiss, Acc. Chem. Res., 2010, 43, 751760.

8 T. Shimizu, M. Masuda and H. Minamikawa, Chem. Rev., 2005, 105, 1401-1444.

9 A. Ajayaghosh and V. K. Praveen, Acc. Chem. Res., 2007, 40, 644-656.

10 B. G. Bag and R. Majumdar, Chem. Rec., 2017, 17, 841-873.

11 P. Moitra, K. Kumar, P. Kondaiah and S. Bhattacharya, Angew. Chem., Int. Ed., 2014, 53, 1113-1117. 
12 S. K. Misra, P. Moitra, B. S. Chhikara, P. Kondaiah and S. Bhattacharya, J. Mater. Chem., 2012, 22, 7985-7998.

13 D. M. Vriezema, P. M. L. Garcia, N. S. Oltra, N. S. Hatzakis, S. M. Kuiper, R. J. M. Nolte, A. E. Rowan and J. C. M. V. Hest, Angew. Chem., Int. Ed., 2007, 46, 7378-7382. 14 S. K. Misra, P. Kondaiah, S. Bhattacharya and C. N. R. Rao, Small, 2012, 8, 131-143.

15 J. Mayr, C. Saldias and D. D. Diaz, Chem. Soc. Rev., 2018, 47, 1484-1515.

16 Z. Yang, G. Liang, L. Wang and B. Xu, J. Am. Chem. Soc., 2006, 128, 3038-3043.

17 P. Broz, S. Driamov, J. Ziegler, N. Ben-Haim, S. Marsch, W. Meier and P. Hunziker, Nano Lett., 2006, 6, 2349-2353.

18 F. J. Ostos, J. A. Lebrjn, M. L. Moy, M. L. Ljpez, A. Sanchez, A. Clavero, C. B. G. Calderjn, I. V. Rosado and P. L. Cornejo, Chem.-Asian J., 2017, 12, 679-689.

19 Y. Jang and J. A. Champion, Acc. Chem. Res., 2016, 49, 21882198.

20 D. Astruc, E. Boisselier and C. Ornelas, Chem. Rev., 2010, 110, 1857-1959.

21 R. Dong, Y. Zhou and X. Zhu, Acc. Chem. Res., 2014, 47, 20062016.

22 D. S. Guo and Y. Liu, Acc. Chem. Res., 2014, 47, 1925-1934.

23 M. Suzuki and K. Hanabusa, Chem. Soc. Rev., 2009, 38, 967975.

24 M. George and R. G. Weiss, Acc. Chem. Res., 2006, 39, 489497.

25 T. S. Ingole, S. S. Kale, S. S. Babu and G. J. Sanjayan, Chem. Commun., 2016, 52, 10771-10774.

26 W. Cai, G. T. Wang, Y. X. Xu, X. K. Jiang and Z. T. Li, J. Am. Chem. Soc., 2008, 130, 6936-6937.

27 J. Zhou, G. Yu and F. Huang, Chem. Soc. Rev., 2017, 46, 70217053.

28 Z. A. Ahmady and K. Kostarelos, Chem. Rev., 2016, 116, 38833918.

29 X. Chi, H. Zhang, G. I. V. Zúñiga, G. M. Peters and J. L. Sessler, J. Am. Chem. Soc., 2016, 138, 5829-5832.

30 B. H. Lipshutz, B. James, S. Vance and I. Carrico, Tetrahedron Lett., 1997, 38, 753-756.

31 D. Parmar, E. Sugiono, S. Raja and M. Rueping, Chem. Rev., 2014, 114, 9047-9153.

32 M. M. Pereira, J. F. Calvete, R. M. B. Carrilho and A. R. Abreu, Chem. Soc. Rev., 2013, 42, 6990-7027.
33 S. Schenker, A. Zamfir, M. Freund and S. B. Tsogoeva, Eur. J. Org. Chem., 2011, 12, 2209-2222.

34 Y. Chen, S. Yekta and A. K. Yudin, Chem. Rev., 2003, 103, 3155-3212.

35 M. Shibasaki and S. Matsunaga, Chem. Soc. Rev., 2006, 35, 269-279.

36 J. M. Brunel, Chem. Rev., 2007, 107, PR1-PR45.

37 G. Von Kiedrowski, Bioorg. Chem. Front., 1993, 3, 113-146.

38 L. E. Orgel, Acc. Chem. Res., 1995, 28, 109-118.

39 D. N. Reinhoudt, D. M. Rudkevich and F. de Jong, J. Am. Chem. Soc., 1996, 118, 6880-6889.

40 J. S. Nowick, Q. Feng, T. Tjivikua, P. Ballester and J. Rebek Jr, J. Am. Chem. Soc., 1991, 113, 8831-8839.

41 B. G. Bag and G. von Kiedrowski, Pure Appl. Chem., 1996, 68, 2145-2152.

42 B. G. Bag, S. Ghorai, S. K. Panja, S. K. Dinda and K. Paul, Prayogik Rasayan, 2017, 1, 74-79.

43 D. Sievers and G. von Kiedrowski, Nature, 1994, 389, 221224.

44 N. Giuseppone, Acc. Chem. Res., 2012, 45, 2178-2188.

45 M. Noji, M. Nakajima and K. Koga, Tetrahedron Lett., 1994, 35, 7983-7984.

46 M. Laupheimer, K. Jovic, F. E. Antunes, M. G. M. Miguel and C. Stubenrauch, Soft Matter, 2013, 9, 3661-3670.

47 P. Patra, A. P. Rameshbabu, D. Das, S. Dhara, A. B. Panda and S. Pal, Polym. Chem., 2016, 7, 5426-5435.

48 X. Ran, Y. Li, Q. Gao, W. Qiu and L. Guo, Asian J. Org. Chem., 2017, 6, 95-101.

49 B. G. Bag, A. C. Barai, K. Wijesekera and P. Kittakoop, ChemistrySelect, 2017, 2, 4969-4973.

50 B. G. Bag, S. Das, S. N. Hasan and A. C. Barai, RSC Adv., 2017, 7, 18136-18143.

51 B. G. Bag and R. Majumdar, RSC Adv., 2014, 4, 53327-53334.

52 B. Sun and D. T. Chiu, Langmuir, 2004, 20, 4614-4620.

53 R. Xu, N. Takahashi and R. J. Simpson, J. Clin. Invest., 2016, 4, 1152-1162.

54 M. Antonietti and S. Foerster, Adv. Mater., 2003, 15, 13231333.

55 S. Dinda, M. Ghosh and P. K. Das, Langmuir, 2016, 32, 67016712.

56 J. Naskar and A. Banerjee, Chem.-Asian J., 2009, 4, 18171823.

57 J. Naskar, S. Roy, A. Joardar, S. Das and A. Banerjee, Org. Biomol. Chem., 2011, 9, 6610-6615. 